\title{
Use of Plasmapheresis in Acute Pancreatitis Secondary to Hypertriglyceridemia
}

\author{
Faydhi $\mathbf{A}^{1}$, Mohidin S., ${ }^{2, *}$, Al Eidarous $\mathrm{S}^{2}$ \\ ${ }^{1}$ Intensive Care Unit, King Abdulaziz University Hospital Jeddah K S A \\ ${ }^{2}$ Nursing Clinical Practice \& Research Unit, King Abdulaziz University Hospital Jeddah K S A
}

Copyright (C) 2015 Horizon Research Publishing All rights reserved.

\begin{abstract}
This article reporting on a case study 21 years old lady diagnosed with acute pancreatitis secondary to hypertriglyceridemia was treated with series of plasmapheresis as treatment modality. The patient came with high triglycerides and cholesterol level, deteriorated and admitted to ICU for ventilation support. Three series of plasmapheresis was done on the consecutive days in ICU. Laboratory results show remarkable changes on both total cholesterol and triglyceride levels reduction by $-11 \%$ to $33.6 \%$ and $20.8 \%$ to $51.8 \%$ respectively. The patient's general condition improve significantly patient was extubated and haemodinamically stable. Patient was transferred to general ward on day $5^{\text {th }}$ of ICU and discharge on the day $13^{\text {th }}$ of hospital admission. Plasmapheresis was proved to be treatment modality for patients with hypertriglyceridemia.
\end{abstract}

Keywords Component, Acute Pancreatitis, Hypertriglyceridemia, Plasmapheresis

\section{Introduction}

A key component in managing acute pancreatitis is the assessment of severity of the patient and underlying cause that leads to this condition. In this case, given patient had a high level of serum triglycerides, it was not possible to utilize the more conventional acute pancreatitis scoring schemes. Plasmapheresis treatment modality was performed for the treatment of hypertriglyceridemia in patients with sudden onset severe hypertriglyceridemia and acute pancreatitis; however, only limited reports of plasmapheresis as a treatment modality have been published.

Plasmapheresis is a procedure where plasma exchange takes place. During the procedure the separation of plasma from blood cells by removing the large volume of plasma and replaced with a colloid solution to maintain oncotic pressure is done which then are returned to the patient body system (Reimann, \& Mason, 1990)

Plasma exchange or commonly known as plasmapheresis has been applied to a wide variety of immunological and non-immunological diseases. In this case it has been used as non-immunological. The plasmapheresis is a treatment of choice by evidence based treatment modality comparing to other conservative modality. It is more efficient and effective. In additional its more required in the case of acute pancreatitis where it is not only treating the hypertriglycedemia it is also eliminate any further complication and risks in this case study.

In this paper the researcher describe the usage of plasmapheresis as a treatment modality for hypertriglyceridemia in a patient with acute pancreatitis.

\section{Clinical Case}

A 21-year-old woman presented to the Emergency Room (ER) with a one-day history of severe epigastric pain and vomiting. The pain was of sudden onset and stabbing in nature, and it radiated to the back. She reported a similar episode about two weeks ago, which warranted medical consultation and admission to the General Surgical Ward; however, the patient was discharged against medical advice.

The patient had a 4 years history of diabetes mellitus under treatment with metformin. She also had a history of hyperlipidemic for which she took no medications. She was admitted in 2010 as a case of diabetic ketoacidosis (DKA) and acute acalculus cholecystitis, which was managed conservatively. The patient had no history of gall stone or fever, and she had no other complains.

On examination the patient was conscious, alert, oriented, and in pain. Her vital signs were as follows: pulse, 130/minute; blood pressure, $116 / 78 \mathrm{mmHg}$, temperature, $36.8^{\circ} \mathrm{C}$; and room air oxygen saturation, $93 \%$. Patient abdomen was tender (generalized moderate tenderness), especially in the epigastrium, with positive bowel sounds. A provisional diagnosis was made in ER as acute pancreatitis due to hyperlipidemia.

Laboratory investigations showed high level of triglycerides, $18.21 \mathrm{mmol} / \mathrm{L}$ (reference range $=0.3-2.30$ ) and total cholesterol $7.11 \mathrm{mmol} / \mathrm{L}$ (reference range $=0-5.20$ $\mathrm{mmol} / \mathrm{L}$ ). 
A computerized tomography scan (CT) of the abdomen revealed a bulky pancreatic head was bulky, with a low attenuation focus in the head and neck of the pancreas associated with marked inflammatory changes around the head and part of the body. These findings were suggestive of uncomplicated mild to moderate acute pancreatitis, according to the modified CT severity index scoring. The result was compared with that of previous scan that was performed on August 14, 2012. The previous focal low-attenuation area at the uncinate process appeared enlarged and measured $2.4 \times 2 \mathrm{~cm}$ (previously $1.3 \times 1 \mathrm{~cm}$, most likely representing a focal area of necrosis. The pancreas was still enlarged, edematous, with severe peri pancreatic inflammatory changes.

\section{Management}

The table below summarizes the management given to this patient while her admission from ER until she has been prepared to discharge from general surgical ward.
The management started by patient was kept nil by mouth (NBM) and started on intravenous fluids in ER. The condition of hyperglycemia was treated using insulin sliding scale at the same time as the low hemoglobin was conquered with blood transfusion.

Patient condition deteriorated and she got into septic shock 48 hours after admission to the ER unit. From the ER patient was admitted to female surgical ward for further management. However the patient condition further deteriorated on the same day. The Intensive Care Unit (ICU) was contacted for the further assessment and patient transferred to ICU on the day of admission. In ICU patient was placed on biphasic positive airway pressure ventilation. Owing to episodes of coffee-ground vomiting, a nasogastric tube was inserted, and the drain yielded $700 \mathrm{ml}$ of coffee-ground liquid. The patient was started on pantoprazole infusion. Further laboratory investigations were performed to monitor patient's lipid profile, full blood count and serum electrolytes.

\section{Table 1 :- The changes in the results of lab tests of the patient before, during and after discharge from ICU.}

\begin{tabular}{|c|c|c|c|c|c|c|c|c|}
\hline & Day 1 & Day 2 & Day 3 & Day 4 & Day 5 & $\begin{array}{r}\text { Day } \\
6\end{array}$ & $\begin{array}{l}\text { Day } \\
7\end{array}$ & Day 8 \\
\hline $\begin{array}{l}\text { Blood } \\
\text { investigations: }\end{array}$ & $\begin{array}{l}\text { Adm } \\
\text { thru ER }\end{array}$ & $\begin{array}{l}\text { Adm } \\
\text { FSW } \\
\text { ICU }\end{array}$ & Dl ICU & D2 ICU & D3 ICU & D4 ICU & Tran FSW & FSW \\
\hline $\begin{array}{ll}\begin{array}{l}\text { Serum } \\
\mathrm{mmolL}\end{array} & \text { sodium } \\
\end{array}$ & 122 & 133 & 142 & 138 & 140 & 137 & 138 & 139 \\
\hline $\begin{array}{l}\text { Serum potassium } \\
\text { mmolL }\end{array}$ & 4.1 & 4.4 & 2.9 & 3.4 & 3.2 & 3.3 & 3.0 & 3.3 \\
\hline $\begin{array}{l}\text { Serum } \\
\text { mmoll }\end{array}$ & 1.4 & 4.4 & 2.4 & 1.6 & 1.3 & 1.3 & 1.4 & 1.9 \\
\hline $\begin{array}{l}\text { Serum creatinine } \\
\text { umollL }\end{array}$ & 83 & 124 & 65 & 55 & 42 & 47 & 44 & 44 \\
\hline $\begin{array}{l}\text { Direct } \\
\text { umoll/L }\end{array}$ & 9 & & & & & & & \\
\hline $\begin{array}{l}\text { Total bilirubin } \\
\text { umollL }\end{array}$ & 26 & 10 & & & & & & \\
\hline $\begin{array}{l}\text { Alkaline } \\
\text { phosphatase (ALP) } \\
\text { U/L }\end{array}$ & 134 & 48 & & & & & & \\
\hline $\begin{array}{l}\text { Aspartate } \\
\text { aminotransferase } \\
\text { (AST) U/L }\end{array}$ & 23 & 90 & 55 & & & & & \\
\hline Albumin g/L & 26 & 21 & 29 & & & & & \\
\hline $\mathrm{WBC} \mathrm{K} / \mathrm{ul}$ & 14.7 & 12.04 & 8.8 & 6.46 & 5.33 & 6.27 & 6.86 & \\
\hline Hemoglobin g/dl & 18.8 & 16.9 & 11.2 & 8.9 & 8.4 & 8.3 & 8.4 & \\
\hline Platelet count $\mathrm{K} / \mathrm{ul}$ & 289 & 349 & 164 & 128 & 111 & 129 & 154 & \\
\hline $\begin{array}{l}\text { Blood glucose } \\
\text { mmoll }\end{array}$ & 23.6 & 13.1 & & & 6.3 & & & \\
\hline Triglycerides & 18.21 & 20.44 & 10.6 & 8.24 & 4.88 & 4.64 & 4.76 & 5.16 \\
\hline Total cholesterol & 7.11 & 5.44 & 3.61 & 3.10 & 2.25 & 2.66 & 3.02 & 2.80 \\
\hline $\begin{array}{l}\text { High-density } \\
\text { lipoprotein (HDL) }\end{array}$ & & 0.20 & 0.12 & & & 0.67 & & 0.38 \\
\hline $\begin{array}{l}\text { Low-density } \\
\text { lipoprotein (LDL) }\end{array}$ & & 1.00 & 0.56 & & & 1.22 & & 1.26 \\
\hline
\end{tabular}


In Day 1 ICU, first plasmapheresis session is done and $1500 \mathrm{~mL}$ of plasma were removed and it's replaced with 500 $\mathrm{mL} f$ albumin and $1150 \mathrm{~mL}$ normal saline with the ratio of $40-50 \%$ o. Repeat laboratory tests showed as in the table display. On day 2 ICU, patient condition deteriorated the patient was intubated and ventilated with pressure-regulated volume control, mode rate 24 oxygen fraction $30 \%$ to maintain oxygen saturation $97 \%$ and SCVO2 75.9\%). Her vital signs were as follows: blood pressure, $115 / 58 \mathrm{mmHg}$; heart rate, 121 beats/minute; and central venous pressure, 17 $\mathrm{mmHg}$ without inotropes support. The patient's abdomen was distended and non-tender. The second cycle of plasmapheresis was done on third day of hospitalization. About $1700 \mathrm{~mL}$ of plasma were removed and replaced with $1200 \mathrm{~mL}$ of normal saline and $500 \mathrm{~mL}$ of albumin. Patient had a temperature of $39^{\circ} \mathrm{C}$ on the day 3 in ICU although other vital signs were in stable range however the patient still had coffee-ground secretions in the nasogastric drain. Laboratory test revealed new labs result as shown in table. The third cycle of plasmapheresis was conducted on day four of hospitalization. The same amount and concentration were given which $1700 \mathrm{~mL}$ of serum were removed and replaced with $1200 \mathrm{~mL}$ of normal saline and $500 \mathrm{~mL}$ of albumin.

On day fourth the patient temperature decreases to low-grade fever $\left(37.8-38^{\circ} \mathrm{C}\right)$. Further blood investigation is done as shown in the table above. For the day 4 ICU admission, patient was extubated, conscious, alert and haemodinamically stable. Patient was started with NGT feeding. From the series of blood result showed TG $4.64 \mathrm{mmol} / 1$ and cholesterol $2.66 \mathrm{mmol} / 1$ with a little rise of WBC 6.27 and same $\mathrm{Hb} 8.3$.

On day 5 of hospitalization at the ICU, the patient was transferred to the General Surgical Ward. Her vital signs were stable, and she was started on oral feeding, which she tolerated well. She was referred for endocrinology follow-up. A repeat CT abdomen showed minimal inflammatory changes in the pancreas, suggesting clinical improvement. The patient was discharged on oral Gemfibrozil $600 \mathrm{mg}$ thrice daily, $4 \mathrm{~g}$ of oral omega-3 prescribed thrice daily, subcutaneous regular insulin 6 units thrice daily before meals, subcutaneous neutral NPH 15 units in the morning and 10 units in the evening, and oral pantoprazole $40 \mathrm{mg}$ daily. She was advised to come back after one month for follow up. The final laboratory test was repeated during clinic visit showed significant normal range results; the patient had a good clinical progression after plasmapheresis. Patient does not complaint of abdominal pain, vomiting, and no coffee ground drainage from the gaster. Patient started with nasogastric feeding and found to be tolerating well (Figure1).

Laboratory results proved that plasmapheresis remarkably reduced both serum triglycerides by $51.8 \%$ after first cycle and improved gradually on second and third cycle (Table 2).

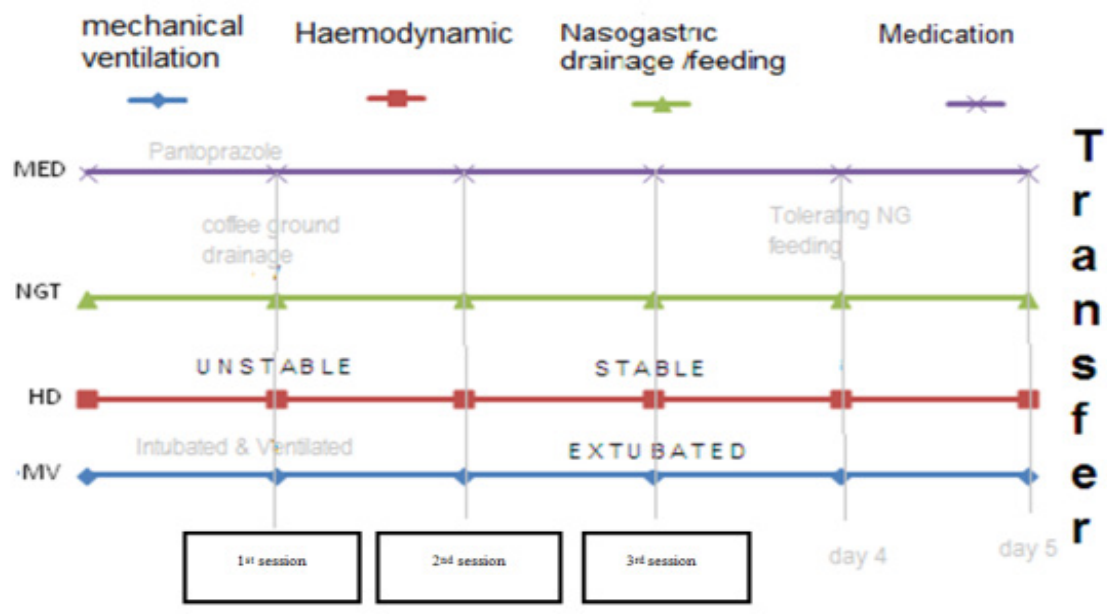

Figure 1. The patient physiological changes after 3 sessions of plasmapheresis

Table 2: results of the blood investigation of triglyceride level in $\mathrm{mmol} / \mathrm{L}$ and total cholesterol level in $\mathrm{mmol} / \mathrm{L}$ and the percentage of the change during after giving three Plasmapheresis sessions

\begin{tabular}{|c|c|c|c|c|c|c|c|c|}
\hline \multirow[t]{2}{*}{$\begin{array}{l}\text { Blood } \\
\text { investigation }\end{array}$} & \multirow{2}{*}{$\begin{array}{l}\text { Before } \\
\text { level }\end{array}$} & \multicolumn{2}{|c|}{$\begin{array}{l}\text { After } 1^{\text {st }} \\
\text { Session of } \\
\text { Plasmapheresis } \\
\end{array}$} & \multicolumn{2}{|c|}{$\begin{array}{l}\text { After } 2^{\text {nd }} \\
\text { session of } \\
\text { Plasmapheresis }\end{array}$} & \multicolumn{2}{|c|}{$\begin{array}{l}\text { After } 3^{\text {rd }} \\
\text { session of } \\
\text { Plasmapheresis } \\
\end{array}$} & \multirow{2}{*}{$\begin{array}{l}\begin{array}{l}\text { Final } \\
\text { result }\end{array} \\
\text { level }\end{array}$} \\
\hline & & level & $\begin{array}{l}\% \text { of } \\
\text { change }\end{array}$ & level & $\begin{array}{l}\text { \% of } \\
\text { change }\end{array}$ & level & $\begin{array}{l}\text { \% of } \\
\text { change }\end{array}$ & \\
\hline $\begin{array}{l}\text { Triglyceride } \\
\text { mmol/L }\end{array}$ & 20.44 & 10.6 & 51.8 & 8.24 & 22.3 & 4.88 & 40.8 & $\begin{array}{l}2.78 \\
(43 \%)\end{array}$ \\
\hline $\begin{array}{l}\text { Cholesterol } \\
\mathrm{mmol} / \mathrm{L}\end{array}$ & 5.44 & 3.61 & 33.6 & 3.10 & 14.1 & 2.25 & 27.4 & $\begin{array}{l}2.5 \\
(11 \%)\end{array}$ \\
\hline
\end{tabular}




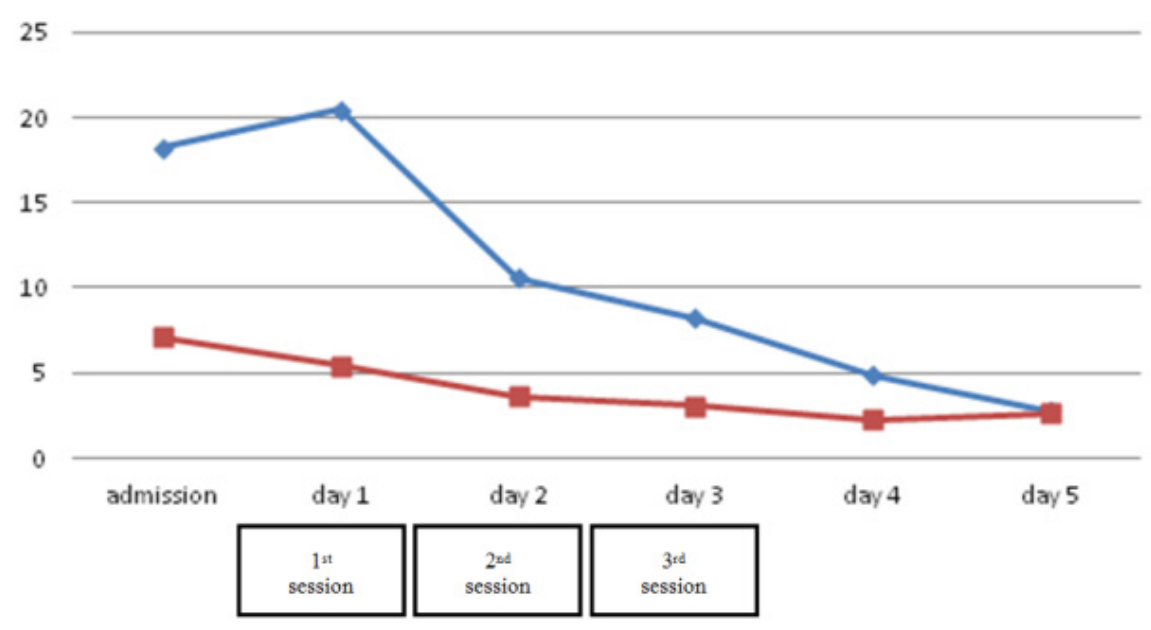

Figure 2. Level of the triglyceride and the cholesterol level after given 3 session of plasmapheresis

Prior to discharge patient's outcome also is confirmed with radiological investigation. Repeated CT scan after the three cycle of plasmapheresis verified that stable appearance of the pancreatitis with mild improvement of the inflammatory changes notified.

Figure 2 above highlight the plasmapheresis remarkably reduced both serum triglyceride and total cholesterol levels reduce from $20.44 \mathrm{mmol} / \mathrm{L}$ to $2.78 \mathrm{mmol} / \mathrm{L}$ and from $7.11 \mathrm{mmol} / \mathrm{L}$ to $2.8 \mathrm{mmol} /$ respectively. Patient general conditions improved from the day 1 till the day 5 admissions where the patient is stable and transferred to general ward before discharge.

\section{Discussion}

This report highlights the case of a young patient with uncontrolled hypertriglyceridemia and acute pancreatitis who benefited from plasmapheresis. The same finding was highlighted by limited few articles (Kadikoylu et al. 4). Kadikoylu et al. suggested that triglycerides that accumulated around the pancreas were hydrolyzed by pancreatic lipase that seeped out of acinar cells, leading to the accumulation of high levels of free fatty acids [2]. This explains the significant reduction happen to this patient lipid profile results after every cycle of plasmapheresis. This was further explored by Gan et al., stating that advocate active steps to lower the levels of precipitating lipid, most notably by removing chylomicrons via plasmapheresis/ therapeutic plasma exchange (TPE) [2]. Another study by Yeh et al. found that roughly two-thirds of cholesterol and triglycerides are removed after single plasma exchange treatment, with an additional benefit seen in the reduction of triglyceride levels after a second treatment [1]. The author further explained that $76.5 \%$ of hyperlipidemic pancreatitis patients treated with plasma exchange recovered completely. However, Yeh et al. did not find that the number of sessions of plasma exchange was linked to survival rates [1]. Subsequent papers have shown a use for long-term plasma exchange/ plasmapheresis in controlling triglyceride levels $[1,3]$. The articles also revealed that an increased risk of complications existed when fresh frozen plasma was used as the replacement fluid, compared with human albumin solution [2]. Most reports on plasmapheresis associated with hypertriglyceridemia typically lower triglyceride levels by $60-70 \%$ in one session [6]. However, single and double filtration plasmapheresis do not selectively remove lipoproteins and triglycerides, and hence coagulation factors and immunoglobulin's also are removed with possible adverse events, including infections [5]. Thus, we chose an approach with selective lipoprotein aphaeresis, although the treatment is not as effective for lowering triglycerides as the plasmapheresis techniques [5]. Selective whole blood lipoprotein aphaeresis is feasible for hypertriglyceridemia, and it causes moderate reduction of triglyceride levels and apparent protection from pancreatitis without the undesired consequences of ordinary plasmapheresis (5). In conclusion this case study expanding further evidence in using plasmapheresis as treatment modality in hypertriglyceridemia patient.

\section{Acknowledgements}

We would like to offer our special thanks to the ICU team and nurses who have contributed in the care of this patient.

\section{REFERENCES}

[1] Reimann, P. M., \& Mason, P. D. (1990). Plasmapheresis: technique and complications. Intensive care medicine, 16(1), $3-10$.

[2] Oh R. C. \& Lanier J. B. (2007). Management of Hypertriglyceridemia. Retrieved from the American Family Physician Web site at www.aafp.org/afp. American Academy of Family Physicians. 
[3] Cahalane A. M., Smith M. J., Ryan J., \& Maguire D. (2012). Case report: Acute Pancreatitis Secondary to Gestational Hypertriglyceridaemia. Hindawi Publishing Corporation Volume 2012, Article ID 627890, 5 pages doi: $10.1155 / 2012 / 627890$

[4] Balachandra S., Virlos I. T., King N. K., Siriwardana H. P., France M. W., \& Siriwardena A. K.. (2006) Hyperlipidaemia and outcome in acute pancreatitis Blackwell Publishing Ltd Int J Clin Pract, 60, 2, 156-159

[5] Nakagawa M., Kimura S., Fujimoto K., Atumi H., Imura J., ... Yokoyama H. (2008) A Case Report of an Adult With Severe Hyperlipidemic During Acute Lymphocytic Leukemia
Induction Therapy Successfully Treated With Plasmapheresis. Therapeutic Apheresis and Dialysis 12(6):509-513 doi: 10.1111/j.1744-9987..00647.x

[6] Hovland A., Hardersen R., Mollnes T. E., Lappegård K. T. (2010). Selective Whole Blood Lipoprotein Apheresis to Prevent Pancreatitis in Drug Refractory Hypertriglyceridemia. JOP. J Pancreas (Online); 11(5):467-469.

[7] Hussain A., Adnan A. \& El-Hasani S. (2012). Small Cell Carcinoma of the Lung Presented as Acute Pancreatitis.Case Report and Review of the Literature. JOP. J Pancreas; 13(6):702-704. 